\title{
PERCURSOS DE VISITA EM SITES DA INTERNET
}

\section{VISITING PATHS ON THE INTERNET SITES}

LUCIA TEIXEIRA*

RESUMO: 0 artigo analisa três modalidades de sites de acervos de arte disponíveis na internet: sites de museus que replicam museus físicos, sites de museus digitais e sites de acervos específicos de arte, usando como exemplos os sites do Louvre, do MASP, do Museu Virtual de Ouro Preto e da Brasiliana Fotográfica. Apresenta características dos sites e descreve seus modos de funcionamento, utilizando a base teórica da semiótica discursiva. A análise discute, inicialmente, a questão do suporte e do plano da expressão e, em seguida, descreve a práxis enunciativa, o sincretismo de linguagens e o ritmo, como procedimentos discursivos que diferenciam e aproximam os três tipos de sites estudados.

PALAVRAS-CHAVE: Sites de acervos de arte. Sincretismo. Práxis enunciativa. Ritmo.

ABSTRACT: This paper analyzes three modalities of art collections available on the internet websites: museums websites that replicate physical museums, digital museums and specific art collections websites, using as examples the websites

* Docente da UFF - Universidade Federal Fluminense. E-mail: luciatso@gmail.com. 
of the Louvre, the MASP, the Virtual Museum of Ouro Preto and the Brasiliana Fotográfica. The paper presents characteristics of the websites and describes their modes of operation, by using the theoretical basis of discursive semiotics. The analysis discusses initially the issue of support and expression plane, and then describes the enunciative praxis, the syncretism of language and the rhythm, as discursive procedures that differentiate and approach the three types of studied websites.

KEYWORDS: Art collection websites. Syncretism. Enunciative praxis. Rhythm.

Nada que se escreva sobre a internet poderá dar conta da transformação radical que a rede trouxe não apenas às comunicações interpessoais, mas também à circulação da pesquisa e ao consequente avanço do conhecimento. Em fluxo contínuo, as informações circulam em velocidade assustadora e acumulam-se em sites, blogs, bancos de dados, portais etc.

Para Canclini (2008, p. 69), "a globalização é um movimento de fluxos e redes, mais do que de entidades visíveis, colecionáveis e passíveis de serem exibidas". Impondo novos arranjos da vida social, no entanto, a internet põe em tensão o conceito de virtualidade, ao transformar fluxos e redes em fórmulas concretas de comunicação, compromisso e trabalho. Com isso, alarga a noção de espaço, desfaz os limites da casa e do escritório, jogando o internauta nas ruas do mundo, relativiza o tempo, ao absorver o sujeito nos links que podem levá-lo indefinidamente em sua busca de informação e lazer, e chega mesmo a fragmentar o navegante que, feliz e realizado nas redes sociais, esconde os desconfortos e insucessos do dia a dia. 
Debruçar-se sobre os hipertextos disponíveis num site significa observar um continuum que se manifesta numa espacialidade estendida e numa temporalidade em fluxo, como sucessão de sobrevires, sem cortes pré-estabelecidos, sem paradas determinadas ou limites fixados. As descontinuidades serão promovidas pelo internauta, por seu gesto de clicar sobre o mouse ou tocar a tela, movimentos do corpo que podem ser significados por uma oposição entre peso e leveza, assertividade e deslizamento, não tanto para indicar que tomaremos aqui o rumo dos estudos do corpo e da sensorialidade na produção do sentido, mas apenas para assinalar, já de saída, que os suportes materiais com que lidamos oferecem, em sua própria natureza de artefato tecnológico e objetos de design, modos de interação com o sujeito operador em si significantes. A cibercultura manifesta-se em diferentes tipos de suportes e cada um deles oferece opções de navegação que, se acessam os mesmos domínios, nem sempre são igualmente adequados aos objetivos de acesso. É mais prático trocar mensagens pelo celular, mas a visita a um site de museu é mais proveitosa em telas grandes de computadores com alta resolução. Ver um filme na Smart TV de grandes dimensões e qualidade de som potente permite fruição mais plena que fazer a mesma coisa num tablet. Aplicativos criados especialmente para celulares comprimem o espaço de navegação e encontram fórmulas rápidas de acesso à rede e aos serviços que oferecem.

0 tamanho, formato e qualidades técnicas e de design do suporte material estabelecem, portanto, acesso diferenciado às informações em circulação na rede, mas não limitam o acesso a ela. Como materialidade, o suporte é o que torna possível e concreto um certo tipo de relação comunicativa. Celulares, computadores e tablets são suportes materiais. Por outro lado, podemos considerar que são também suportes, em ou- 
tra dimensão, mais simbólica e ligada a um domínio particular de comunicação, os tipos de páginas oferecidas. Um blog, um jornal on-line, um site e um portal são suportes, locais de inscrição de tipos e gêneros diferentes de textos ou hipertextos. Da mesma maneira que um jornal impresso é manifestado na materialidade do papel, nele se inscrevem editoriais, charges, reportagens e outros gêneros da esfera jornalística, que se particularizam para atender às coerções do suporte formal em que se inscrevem.

A análise dos suportes e gêneros digitais vem-se servindo das descrições já feitas de textos que não tiveram sua origem nas mídias digitais e que foram depois retomados em novo formato. Jornais on-line, periódicos científicos, revistas de atualidades são suportes que tendem a ser analisados em comparação com os formatos impressos, trazendo a novidade da atualização constante e da interação mais efetiva com o internauta. A descrição da conversa travada nas redes sociais aproveita conceitos da análise da conversação e dos estudos de texto e discurso, como faz Diana Luz Pessoa de Barros, por exemplo, ao analisar a comunicação na internet. A autora recupera as diferenças entre língua oral e língua escrita para concluir que:

Os textos na internet ora se aproximam da caracterização temporal ideal da fala, como nos "bate-papos" por computador, que não são planejados antecipadamente, apresentam traços de re-elaboração e são fragmentados, ora da escrita, como na troca de e-mails, em que não há concomitância temporal, nem marcas de formulação. Ocupam, porém, posições sempre intermediárias entre os pontos extremos da fala e da escrita ideais (BARROS, 2014).

Nesse tipo de descrição, tem-se um ponto de partida 
conhecido e as páginas ou procedimentos próprios da internet são analisados sobretudo como remediação de um outro meio: do impresso para o digital, dos terminais de atendimento aos aplicativos de celular (no caso, por exemplo, do acesso a uma conta bancária), da oposição entre língua falada e língua escrita a um meio-termo que mistura as duas formas etc. Já manifestações produzidas exclusivamente para as mídias digitais, como sites, blogs e portais, estão a merecer estudo mais detalhado de seu modo de funcionamento, com procedimentos discursivos particulares e gêneros próprios da comunicação em rede.

Neste artigo, analisaremos, em linhas gerais, três tipos de sites de acervo de objetos de arte disponíveis na internet: 1. os sites de museus, que constituem propostas de replicação dos museus concretos, como os sites do Louvre ou do Museu de Arte de São Paulo (MASP); 2. os sites de museus virtuais, aqueles que só existem nas nuvens da cibercultura, seja sob a forma de um museu temático, como o da RTP (Rádio e Televisão Portuguesa), seja sob a forma de um portal de entrada a percursos de visitação, como o do Museu Virtual de Ouro Preto; 3. Os sites de acervos digitalizados, disponíveis para consulta, download e compartilhamentos, como o da Brasiliana fotográfica, fruto de uma parceria entre o Instituto Moreira Salles e a Fundação Biblioteca Nacional, que contém centenas de fotografias de aspectos variados da cultura brasileira.

Para observá-los, partiremos da concepção de que sites são manifestações multimodais submetidas a uma práxis enunciativa que lhes confere unidade de sentido, por meio de parâmetros de organização e design, recorrências temáticas e figurativas e um ritmo próprio. 0 efeito de unidade é produzido pela resolução sincrética das linguagens em jogo, obtida pela articulação de todos esses elementos. Em sites de acervo 
de arte, a temática desenvolve-se no campo estético, com variações que podem ir de períodos da história da arte a eventos específicos, de técnicas a estilos, de obras canônicas à arte de rua. Dentro desse campo, temas como beleza, tradição, novidade, elevação se concretizam nas figuras de artistas, obras, exposições. Se o campo semântico já oferece coerções ao discurso, definindo estilos e estabelecendo limites e demarcações de assuntos a tratar, parece-nos ser a expressão visual da página, com os recursos materiais das linguagens mobilizadas e as formas de interação que oferece, o ponto central de uma organização sincrética à qual se imprimirá um ritmo de leitura.

\section{Sincretismo de linguagens}

A semiótica recusa a ideia de soma de códigos e não trabalha com particularidades das substâncias materiais das linguagens, mas com a depreensão de uma unidade de sentido. Uma intervenção enunciativa, consolidada numa práxis, opera correspondências entre um plano de expressão e um de conteúdo. Um texto verbo-visual, como a capa de um livro ou revista, um cartaz ou um folder de divulgação, será considerado uma totalidade material visual, com um plano de expressão constituído por elementos como fontes tipográficas (tipo, tamanho, cor), imagens (fotografias, gráficos, colagens, mapas) e mancha ocupada pelo texto, em relação com os espaços brancos (margens, limites, vazios). Serão também observados os elementos verbais, em sua qualidade de som e em seus arranjos sintático-semânticos. As correspondências e dissonâncias entre organização visual e expressão verbal produzirão a unidade de sentido que, a partir do plano da expressão, se estenderá ao plano do conteúdo. Em regimes de contenção ou de 
expansão, os elementos visuais e verbais criarão efeitos como os de compacto/difuso, cheio/vazio, rarefeito/excessivo, que definirão estilos sóbrios, elegantes, derramados, exuberantes e assim por diante. 0 esforço da análise será sempre o de, tendo partido de segmentações, divisões e fragmentações, reunir todos os elementos numa interpretação que restitua a unidade de sentido ao texto.

Na página inicial de um site como o do museu do Louvre $^{1}$, há pouco espaço branco, nenhuma margem, ocupação total da tela, e mesmo além dela, com necessidade de acionamento da barra de rolagem. Já no site do $\mathrm{MASP}^{2}$, há menos imagens e mais espaço branco. A imagem principal da tela do MASP se altera três vezes, enquanto a do Louvre, cinco vezes. Na tela do MASP, apenas essas imagens aparecem, sucedendo-se para anunciar diferentes exposições ou campos de atuação. Já na tela do Louvre, abaixo das imagens que se alternam, aparecem outras seis imagens fixas, sugerindo desde percursos de visita ao museu à oportunidade de contribuir para seu funcionamento, por meio de doações. A topologia do site do Louvre e seu preenchimento com muitos quadros e cores se opõe à topologia mais limpa do MASP, com poucas manchas de cor e menor quantidade de imagens. Também em relação aos links oferecidos, a profusão do Louvre se opõe às restrições do MASP. Se digitarmos no programa de busca de cada site o nome Rembrandt, sem considerar a enorme diferença no número de obras (não entraremos aqui nas questões históricas, políticas e econômicas que determinam essa diferença), observa-se um efeito de expansão no Louvre, com dados sobre cada obra seguidos de estudo crítico,

1 Disponível em: 〈http://www.louvre.fr〉. Acesso em: 11 dez. 2015.

2 Disponível em: 〈http://masp.art.br〉. Acesso em: 11 dez. 2015. 
e o efeito contrário, de comedimento e economia, no site do MASP, que oferece apenas os metadados da obra. Em ambos os sites, se pode ter a imagem ampliada, em boa resolução. Os efeitos de quantidade, expansão e acumulação do Louvre se contrapõem aos de seleção, contenção e rarefação do MASP, opondo um estilo grandioso a outro comedido.

Os aspectos visuais cromáticos (cor e luz), eidéticos (forma e tamanho) e topológicos (direção, distribuição e movimento no espaço) submetem-se à práxis enunciativa de preenchimento da tela, o que tanto reforça padrões esperados - exibição das imagens correspondentes a exposições em destaque, elementos que afirmam a identidade do museu, como repetição do nome e de uma cor ou detalhe arquitetônico a ele associado, seções fixas previsíveis, como as de serviços, acervo e exposições - quanto surpreende pela novidade, em procedimentos como reduzir a identidade do museu a uma faixa de cor (veja-se a barra inferior vermelha das páginas do MASP), ou recortes arquitetônicos (tais como as formas da pirâmide do Louvre que transbordam das laterais da tela). Denis Bertrand, em seu estudo clássico sobre enunciação, diz que a práxis enunciativa se faz de uma relação dialética entre sedimentação e inovação que "questiona [...], prioritariamente, a espessura cultural do sentido" (BERTRAND, 2003, p. 88).

Sites de museus, multissensoriais e interativos, devem buscar a novidade que atraia o internauta, apele a seus sentidos e estimule sua busca intelectual. A cibercultura é apressada, acelerada, exige sempre a substituição, a surpresa. A multiplicação de apelos na rede exige dos sites recursos que imponham ao internauta paradas no fluxo da navegação. 0 museu é institucional, tem funções estabelecidas (guardar, preservar, exibir etc) e um papel educativo a cumprir. Nessa linha tênue entre atrair sem apelos e educar sem didatismo, o 
site de museu tende a repetir, como temos mostrado em trabalhos anteriores (TEIXEIRA, 2011, 2012, 2013), a imagem do museu físico, reproduzindo o estilo que o define e consagra.

Se o museu do Louvre se abre para os tempos do espetáculo, transforma seus saguões em palcos, promove cursos e visitas guiadas para atrair novos visitantes, mantém, no entanto, firme a imagem da tradição e respeitabilidade tão visível em seus acervos quanto no projeto arquitetônico que inicia sua história em 1546. Este próprio projeto, aliás, com os acréscimos dos séculos, foi incorporando as culturas de época. A chegada à pirâmide corresponde aos apelos do espetáculo, mas as pirâmides são acréscimos que não tocam na solenidade da arquitetura clássica do palácio. 0 mesmo ocorre no site, que acolhe a novidade sob a forma da profusão de estímulos visuais, mas resguarda a identidade clássica do museu francês.

O MASP, projeto de Assis Chateaubriand, que tem início em 1947, atinge sua forma atual em 1968, no belo prédio da Avenida Paulista, projeto de Lina Bo Bardi que privilegia o espaço livre, seja no vão famoso, na praça que se forma sob ele, ou no trânsito de pessoas nas galerias de exposição, com as obras penduradas nos famosos cavaletes de cristal. 0 espaço amplo e livre quer acolher o movimento, incorporar o que está fora do prédio, permitir a circulação, fazer significar o vazio. Assim também ocorre com o site, mais feito de espaços brancos que de imagens coloridas, de intervalos que de preenchimentos.

A gradação que vai do maior ao menor impacto sugere, no caso do Louvre, mais intensidade, indicada pela profusão, tendendo para o excesso, de imagens e informações, sobreposta a maior extensidade, associada à totalidade da ocupação do espaço; no caso do MASP, há menos intensidade, 
detectada no comedimento visual, sobreposta a menor extensidade, associada à parcialidade do espaço ocupado. A relação conversa sugere o autocentramento dos sites sobre a identidade dos próprios museus. 0 Louvre constrói um éthos imponente, poderoso, dotado de saberes que cobrem, em grau máximo, toda a vasta gama de ações predicativas próprias de um museu de arte: guardar, exibir, informar, explicar, avaliar. O MASP, menos poderoso, imponente e dotado de saberes, revela capacidade mais limitada de atendimento às expectativas dos visitantes. Os sites ilustrariam, assim, a identidade de um enunciador que oscila entre a completude e a falta, e, por meio de recursos de persuasão diluídos entre esses tipos de poder, propõem a seus enunciatários práticas de visita.

Os modos de organizar visualmente a informação nos sites começa a impor a necessidade de falar de ritmo e de sua intervenção no acesso às páginas.

\section{Ritmos dos percursos}

Paz (2012. p. 74) diz que "A linguagem nasce do ritmo" e a afirmativa pode ser compreendida em duas perspectivas. Na primeira, refere-se às origens da linguagem e parece sugerir que as manifestações rudimentares da linguagem verbal, com grunhidos e barulhos imitativos da natureza, tenham cedido aos movimentos do próprio corpo, aos impulsos e refluxos da respiração e aos intervalos de espera e repetição entre um e outro som natural. Na segunda perspectiva, a linguagem, tomada como sistema dotado de plano da expressão e plano do conteúdo, manifesta-se em objetos concretos e, nessa situação, o ritmo é aquilo que, entre o silêncio e o som, entre o branco do papel e o preto do traço, faz palpitar o movimento dos sen- 
tidos num texto. Na primeira perspectiva, estaríamos à procura daquilo que Zilberberg (2010, p. 5) chamou "o mito do ritmo", uma espécie de busca das origens em ritmos biológicos ou cosmológicos. Na segunda, Paz se juntaria àqueles que, em campos como os da Estilística, Teoria da Literatura e Estética buscam descrever o ritmo com que as palavras se encadeiam em versos ou na sequência das frases, ou em que as marcas de pinceladas promovem acelerações numa pintura, ou ainda em que gestos repetidos e lentos desaceleram uma dança.

Baxandall (2006, p. 34) alerta para a incompatibilidade formal entre o ritmo com que percorremos um quadro com o olhar e o ritmo com que organizamos palavras e conceitos. Para ele, ritmo se associa tanto a um movimento de corpo, que envolve olhar e gesto, quanto a uma operação intelectual de seleção e combinação. Na afirmativa de Baxandall, o sensível se associa à visibilidade da pintura e o inteligível à racionalidade da organização verbal. 0 sintagma ritmo da pintura naturaliza-se e, ainda que lhe falte definição formal, passa a designar alguma coisa ligada ao movimento e ao deslocamento no espaço. Da mesma maneira, os antigos tratados de estilística mencionam a questão do ritmo como se naturalizada estivesse, incorporando-a ao discurso, sem formalização conceitual. Veja-se, por exemplo, a primeira menção a ritmo que aparece no clássico Estilística da língua portuguesa, de Rodrigues Lapa, no comentário a um "passo de Lima Barreto":

A forma fugace, por fugaz, não se deve apenas a um propósito de latinização do vocábulo; é também evidente nela uma intenção rítmica, um arredondamento fônico mais ajeitado à pronúncia brasileira (LAPA, 1998, p. 46).

Para a semiótica, todo texto é uma unidade rítmica e o ritmo é definido como a incidência da tonicidade, subdimen- 
são da intensidade, sobre a temporalidade, subdimensão da extensidade (cf. ZILBERBERG, 2006). Ora, se a semiótica é uma teoria geral da significação e se define o ritmo por meio da correlação entre os dois eixos que configuram o campo de presença do sujeito no mundo, parece que estamos diante de uma nova possibilidade de reflexão sobre a questão do ritmo, em que se associam a formalização do conceito e a integração das dimensões sensível e inteligível.

É com seu corpo que o homem se relaciona com o mundo e corpo não é só fisicalidade, mas é também afetividade e tensividade. Do ponto de vista do sujeito, a presença é apreendida como espanto, o súbito e o efêmero desestabilizando o hábito. Como se fosse possível olhar de novo e ver diferentemente, sentir de outro modo, para pensar e viver o novo, o que faz sentido. Por essa razão, uma semiótica da presença vem sempre associada a uma compreensão poética do sentido. Assim como a literatura e a pintura, a música e a escultura são modos de apontar para uma possibilidade de leitura diferenciada em relação à grade convencional de compreensão do mundo, assim também, na vida cotidiana, uma espera pode oferecer ao olho, ao tato, aos modos sensíveis de relação com o mundo, novas possibilidades de sentido.

No espaço tensivo, entre espera e distensão, existe um complexo fórico que funciona como ritmo. A duratividade dos acontecimentos rotineiros é subitamente interrompida por um acontecimento inesperado; uma subtaneidade tônica altera o ritmo de uma duração átona. É esse movimento rítmico que transforma o sujeito em espera num sujeito afetado, num sujeito que, tocado por um afeto eufórico, buscará a fusão, a inclusão, o encaixe, a adesão a essa fala que o mobilizou; poderá, entretanto, o sujeito ser tocado por um afeto disfórico, o que implicará sua exclusão, separação, 
disjunção daquilo que o inquietou. De uma maneira ou de outra, produziu-se sentido, interrompeu-se a continuidade, por meio de um súbito acontecimento ao qual se sucederá nova continuidade, mas em outro regime de sentido.

A semiótica vem formalizando categorias para operar a descrição desses acontecimentos. Os dados tensivos oscilam numa escala entre espera e distensão, submetida à ação do tempo, que pode tanto estar marcado como ritmo, num andamento lento ou acelerado, quanto pode estar definido, em relação ao aspecto, como pontualidade em oposição à duratividade. 0 sujeito imerso no tempo é também o sujeito integrado a um espaço, em que profundidade e superficialidade são os operadores da relação. Essa imersão fórica, estado inicial da relação do sujeito com o mundo, vai se manifestar em diferentes níveis no percurso de busca de valores empreendido pelo sujeito, como emoção, síncope da duratividade, como paixão, efeito da duratividade, como um sentimento, que assegura e torna lento um estado durativo, como ação, recorte narrativo sobre o fundo da temporalidade e da espacialidade, como discurso, realização totalizante e concreta de todas as possibilidades.

Para o analista, o percurso se faz inversamente: é a partir do discurso que se pressupõem as etapas tensivas, da mesma maneira que já se identificavam os níveis semionarrativos prévios ao discursivo. São as predicações, as aspectualidades, a figuratividade, o estilo, as marcas do plano da expressão que indicarão aquilo que primeiro afetou o sujeito em seu movimento no mundo e o modo como esses afetos, paixões, arrebatamentos, ritmos, gradações disseminam-se e concretizam-se na materialidade mesma do discurso. A análise do ritmo, assim, se está submetida a uma metodologia que considere como ponto de partida abrangente a incidência da tonicidade sobre a tem- 
poralidade, terá como ponto de chegada obrigatório a particularidade discursiva e material do objeto semiótico.

Cada primeira página de um site de museu, por meio dos arranjos próprios de todo plano de expressão marcado por elementos visuais, oferece ao internauta uma rede de movimentos e percursos, concebidos como direções rítmicas. Ora propondo acelerações, como quando ocorre acúmulo de elementos ou imagens em alternância, ora desacelerações, presentes em espaços mais limpos e com predomínio de imagens fixas, o gesto enunciativo deixa-se atravessar pela articulação de tempo e espaço na linha da extensidade, buscando intervalos ou pontos de intensidade que possam atrair o espectador. Tanto do ponto de vista do impacto sofrido pelo internauta em seu acesso ao site, quanto sob a perspectiva da própria sugestão de links e pontos de apoio no acesso, um site oferece marcas de parada, de continuação, retorno ou abandono, por meio das quais se estabelece a interação entre os sujeitos inscritos na superfície de acesso.

O movimento do sujeito é sempre o de situar-se num tempo e espaço de acolhimento, em que ele regule a irrupção dos afetos:

0 'eu' semiótico habita um espaço tensivo, ou seja, um espaço em cujo âmago a intensidade e a profundidade estão associadas, enquanto o sujeito se esforça, a exemplo de qualquer vivente, por tornar esse nicho habitável, isto é, por ajustar e regular as tensões, organizando as morfologias que o condicionam (FONTANILLE; ZILBERBERG, 2001, p. 128).

A página do site pode ser vista como esse espaço tensivo habitado por sujeitos em interação. Funciona, na relação entre actantes, tempo e espaço, como um campo de presença, modulado por diversas combinações de presença e ausên- 
cia. Um enunciador mais poderoso, como o Louvre, convoca um enunciatário disponível para a navegação mais acelerada, com várias marcas de descontinuidade no percurso e, ao mesmo tempo, pontos de parada mais durativos, com textos explicativos, sugestões de links pertinentes à busca, ampliação do assunto buscado. Já um enunciador caracterizado pelo comedimento, como o MASP, espera um enunciatário interessado em percursos menos acelerados, menor número de paradas, ainda que sejam mais curtas, marcadas por textos breves, informações básicas e pouca possibilidade de ampliação da busca. Ambos os sites propõem operações de triagem ou de mistura, tanto oferecendo a possibilidade de escolha de valores de absoluto (um pintor, uma tela, um estilo) quanto de valores de mistura (o acervo, as atividades museológicas periféricas, como cursos e eventos, as buscas temáticas). No primeiro caso, a navegação é desacelerada e em profundidade. No segundo, acelerada e superficial.

Isso ocorre porque aos percursos possíveis correspondem modos de interação, que podem estar sugeridos nos próprios sites, a partir dos perfis de seus enunciadores, ou se baseiam nos modos de ser dos sujeitos da busca, mais interessados, disponíveis, inquietos, acomodados etc. Assim, por exemplo, quanto mais interessado o internauta estiver em pontos específicos ou em aprofundamento do universo de informações, mais ele promoverá operações de triagem, particularizando e afunilando a busca; se seu interesse, entretanto, for o de expandir a busca, com sucessivas misturas e fragmentações, sobem então muito as chances de surpresas e desvios. Enquanto o fechamento do texto serve à profundidade e modaliza-se pelo saber, a abertura pode resultar na superficialidade e dispersão e estar modalizada por um não saber que poderá ser mantido. 
Diante de um site, de que modo o sujeito movimentará corpo e olhar? Que escolhas fará, que preferências decidirão seu caminho? De que modo intervirá? Com o acatamento passivo dos percursos mais rotineiros, das buscas mais elementares? Com a dispersão da procura desinformada? Com a recusa da facilidade e adesão ao aprofundamento e à concentração? As escolhas não correspondem a tipos de internautas, mas a objetivos de leitura e estarão dadas na virtualidade conceitual do hipertexto, que não é nem ilusório nem desmaterializado, não é uma presença, mas um devir. A virtualidade do hipertexto está em sua qualidade de configurar tendências, forças, finalidades e coerções que a atualização de um texto resolverá.

0 ritmo oscilará entre acelerado e desacelerado no entrecruzamento de todas essas variáveis. Espaços mais restritos, com buscas mais entrecortadas e sujeitos mobilizados pelos valores de mistura tendem a exigir aceleração. Já deslocamentos em espaços mais amplos, com buscas mais aprofundadas e sujeitos moldados pelo interesse na triagem tendem à desaceleração. Entre um e outro ponto máximo, variáveis podem ocorrer e impor gradações rítmicas da prática da visita.

\section{Espaços átonos e tônicos}

Ao estudar o conceito de práxis enunciativa, Fiorin (2010, p. 62) mostra que "o enunciador, no momento da enunciação, convoca, atualiza, repete, reitera um 'já dado' (gêneros, modos de dizer etc.), mas também o revoga, recusa-o, renova-o e transforma-o." A oscilação entre repetição e mudança determina o grau de tonicidade de um texto. A manutenção do já esperado garante manifestações mais átonas e desaceleradas e o excesso de novidades gera textos mais tônicos e 
acelerados. A oposição entre um best-seller e uma obra-prima pode exemplificar os polos de ocorrência dos graus diferentes de intensidade. Quanto mais estímulos que gerem o susto, o impacto e a novidade, mais tonicidade; quanto mais repetição de padrões esperados, maior a atonicidade. Um discurso político de palanque, por exemplo, disfarça a atonicidade das promessas sempre repetidas por meio de recursos retóricos tônicos, ligados ao plano da expressão oral, como modulações do tom da voz, entonações ascendentes e firmes e gestualidade dramática. Um livro de autoajuda instala-se no conforto da leitura pouco inquieta pela repetição de fórmulas banais. Uma autobiografia literária, se também oferece exemplos de luta e superação, espera e determinação, dirige-se ao leitor inquieto que espera impactos no tratamento da linguagem e nos modos de narrar. Há sempre, em todo texto, um ajuste que se adequa a gêneros e leitores, e regula a presença do surpreendente na continuidade do já conhecido.

Nos sites de acervos de arte, há uma práxis que repete padrões de busca e organização, instalando-se uma certa regularidade que proporciona conforto ao internauta. Já se sabe que um site de museu dará acesso ao acervo, por meio de mecanismos de busca variados (artista, obra, período etc), oferecerá recortes das exposições e trará links para atividades mais periféricas, como cursos, lojas, eventos etc. Em meio a essa previsibilidade, rupturas não são comuns, mas os modos de manipular os recursos da internet e os arranjos do plano de expressão podem variar e instalar zonas de impacto e tonicidade. Assim, por exemplo, acessar o site do Louvre e ver, em meio à alternância das imagens de exposições em andamento, o recorte de uma imagem clássica de pintura de criança, fazendo apelo, por meio de um balão com a frase “J'aime (o verbo tendo sido substituído pelo traçado de um coração) le Lou- 
vre", à descoberta do museu em família e à adesão à Sociedade de Amigos do Museu, causa surpresa, tanto pelo inesperado do balão de fala sobre a imagem quanto pela inclusão do tema da manutenção do museu em meio às imagens de convite às exposições. Uma outra forma de encantamento ocorre no site do MASP, com a possibilidade de, clicando num link, percorrer o vídeo da grande sala do Museu, com as obras penduradas em seus famosos cavaletes de cristal (na verdade, de vidro). Passamos então do plano de expressão para o do conteúdo e o impacto do conjunto de obras assombra o internauta com a força e beleza de seu arranjo no espaço. São inúmeros os recursos que podem surpreender e romper a expectativa das seções de praxe e dos apelos convencionais. A práxis enunciativa da organização visual de conteúdos na tela envolve o internauta, oferecendo-lhe tanto a segurança de percursos previsíveis quanto a possibilidade de encantamento, por meio de pequenas iniciativas originais e impactantes.

Já nos sites de acervos com restrita possibilidade de navegação, a surpresa tende a ser rarefeita, os padrões repetidos se acentuam e os roteiros e percursos são esperados. No site do Museu Virtual de Ouro Preto ${ }^{3}$, abaixo da imagem de um retábulo de altar, aparecem duas opções de navegação. Do lado esquerdo da tela, oferece-se um "tour virtual das igrejas". Do lado direito, três pequenas faixas verticais funcionam como links para três percursos - "cidades coloniais", "religião" e "artes e ofícios" - que levam a textos explicativos, sem ilustrações. No tour pelas igrejas, há o recurso de mover a imagem, criando-se a ilusão de movimento da visita e apropriação do espaço global exposto. Em alguns pontos marcados na tela, aparece a identificação da obra, mediante toque do mouse.

3 Disponível em: http://www.museuvirtualdeouropreto.com.br/index.html〉. Acesso em: 12 dez. 2015. 
Também no site da Brasiliana fotográfica ${ }^{4}$, há pouca surpresa, embora sejam mais amplas as possibilidades de navegação. Além do acervo, disponível por quatro critérios de busca (data, autor, assunto, local), há destaques para exposições temporárias, cujos projetos curatoriais são apresentados em textos introdutórios. Qualquer busca acaba numa foto com os metadados correspondentes, não havendo expansão das informações para textos críticos ou informativos. 0 site da Brasiliana fotográfica, com organização visual limpa e amigável, oferece caminhos de acesso marcados por regularidade, desaceleração e previsibilidade. 0 site do Museu Virtual de Ouro Preto, embora com imagens de impacto e pontos de tonicidade (a circulação pelas igrejas; o destaque das obras), tem enfraquecidos os recursos de impacto pela baixa tonicidade dos demais links, que não só desaceleram a navegação, mas frustram a expectativa do visitante.

Os sites de acervo específico, de modo geral, caracterizam-se por redução e condensação do espaço, desaceleração, programação visual convencional e economia de recursos, com efeito de atonicidade, na comparação com os sites de museus.

\section{Os sentidos da arte}

Em todos os sites aqui brevemente analisados, estamos diante de coleções em que se estabelecem conexões estéticas entre a experiência histórica e singular da vida e os objetos que a representam e constituem, por força de fissuras ou adensamentos dos sistemas significantes das linguagens. A visita concreta e a navegação on-line possuem igualmente a 
capacidade de replicar formas de vida que costumam convocar sujeitos interessados e inquietos, apressados e dispersivos, passionais e comedidos.

Deloche, em seu livro sobre museus virtuais, acentua que a reversibilidade ilimitada da visão na tela, ou seja, a possibilidade de ir e voltar sobre a imagem numa janela, faz com que tenhamos passado de uma lógica de consecução linear a uma lógica de coexistência, de correspondência e de interconexão reticular. Nessas idas e voltas, a imagem-texto que se apresenta deve ser tratada como "um mapa, uma carta geográfica ou como uma matriz de sentidos" (DELOCHE, 2001, p. 5). Mantêm-se, para ele, as funções primordiais do museu: fazer-ver, guardar, conservar, mostrar, divulgar, ensinar, comparar, relacionar.

A ideia de matriz, a partir da qual se pode, na sucessão de cliques ou toques, produzir uma rede quase infinita de sentidos, aproxima-se da concepção de hipertexto, nos termos de Lévy (2006, p. 33): "conjunto de nós ligados por conexões". No entanto, as opções são controláveis e os percursos, limitados. Os internautas, distribuídos num arco semântico de papéis temáticos que oscilam do interessado e compromissado ao dispersivo e curioso, e de ritmos que instituem gradações entre controle e acaso, executam movimentos sequenciais, sincopados, repetitivos, bruscos ou desacelerados, que definem modos de ser e de estar na rede e no mundo. Nos sites de acervos específicos, o internauta se vê diante de página de poucos apelos, com diagramação limpa e discreta e percursos de busca simples e limitados. Predomina aí o mecanismo da triagem, fazendo supor um internauta voltado para interesses específicos, em busca de profundidade na navegação. Ao contrário de sites de museus, que se abrem para percursos variados e tornam mais possível, de um lado, a surpresa das 
descobertas, e, de outro, a dispersão da busca, os sites específicos contêm o gesto do internauta e regulam a possibilidade do acontecimento estético derivado do choque do inesperado, por meio de mecanismos expressivos como a imobilidade das imagens, a presença de legendas e textos explicativos e os recursos mínimos de expansão das fotos.

De modo geral, a contemplação digital diminui o impacto da presença viva da obra diante do espectador nas salas de exposição. No entanto, o prazer estético que advém do impacto das rupturas e surpresas em relação à vida cotidiana, feita de exercício e rotina, permanece vivo como promessa de sentidos na tela dos computadores. Os sites de acervos artísticos permitem, eles também, a redescoberta de cenas e pessoas, paisagens e movimentos, em arranjos de linguagem que os recursos da informática permitem isolar, ampliar, movimentar. A observação atenta sempre poderá recuperar o impacto e a intensidade de uma presença que, embora multiplicada, repartida, compartilhada, repetível, recorrente, é, ao mesmo tempo, única em cada situação de acesso à máquina e ainda capaz de provocar a inquietação e a surpresa com que os acontecimentos estéticos costumam desestabilizar a percepção contínua do mundo.

\section{REFERÊNCIAS}

BARROS, D.L. P. 0 discurso intolerante na internet: enunciação e interação. In: XVII CONGRESSO INTERNACIONAL DA ASSOCIAÇÃO DE LINGUÍSTICA E FILOLOGIA DA AMÉRICA LATINA (ALFAL), 2014, João Pessoa-PB. Anais eletrônicos... João Pessoa, 2014. Disponível em: ‘http://www.mundoalfal.org/ CDAnaisXVII/trabalhos/R0716-1.pdf). Acesso em: 13 dez. 2015. 
BAXANDALL, M. Padrões de intenção: a explicação histórica dos quadros. São Paulo: Companhia das Letras, 2006.

BERTRAND, D. Caminhos da semiótica literária. Trad. Grupo CASA. Bauru, SP: EDUSC, 2003.

CANCLINI, N. G. Leitores, espectadores e internautas. São Paulo: Iluminuras, 2008.

DELOCHE, B. Le musée virtuel. Paris: PUF, 2001.

FIORIN, José Luiz. Práxis enunciativa. In: PERNAMBUCO, J.; FIGUEIREDO, M. F.; SALVIATO-SILVA, A. C. Nas trilhas do texto. Franca, SP: Universidade de Franca, 2010. [Coleção Mestrado em Linguística]. p.53-73. Disponível em: ‘ttp://publicacoes. unifran.br/index.php/colecaoMestradoEmLinguistica/ article/view/329/25〉. Acesso em: 13 dez. 2015.

FONTANILLE, J.; ZILBERBERG, C. Tensão e significação. Trad. Ivã Carlos Lopes; Luiz Tatit e Waldir Beividas. São Paulo: Discurso Editorial; Humanitas; FFLCH/USP, 2001.

LAPA, M. R. Estilística da língua portuguesa. São Paulo: Martins Fontes, 1998.

LÉVY, P. As tecnologias da inteligência. Trad. Carlos Irineu da Costa. São Paulo: Ed.34, 2006.

PAZ, O. 0 arco e a lira. Trad. Olga Savary. São Paulo: Cosac Naify, 2012. 
TEIXEIRA, L. Museus on-line: novas práticas de visita. In: TEIXEIRA, L.; CARMO JR., J.R. do (Org.). Linguagens na cibercultura. São Paulo: Estação das Letras e Cores, 2013. p.13-35.

TEIXEIRA, L. Museus on-line: entre contemplação e interação. Comunicação apresentada na II Jornada Linguagens na Cibercultura. Niterói: UFF, 2012.

TEIXEIRA, L. Para uma metodologia de análise do hipertexto. Comunicação apresentada na I Jornada Linguagens na Cibercultura. Niterói: UFF, 2011.

ZILBERBERG, C. Observações sobre a base tensiva do ritmo. In: Estudos semióticos, v.6, n.2, p.1-13, nov, 2010. Disponível em: 〈http://www.fflch.usp.br/dl/semiotica/es/ eSSe62/2010esse62_czilberberg.pdf〉. Acesso em: $14 \mathrm{dez}$. 2015.

ZILBERBERG, C. Síntese da gramática tensiva. Significação, São Paulo, n. 25, p. 163-204, jun, 2006.

Artigo recebido em setembro de 2015 e aprovado em novembro de 2015.

Disponível em: http://seer.fclar.unesp.br/casa 